\title{
Speleothem Laminae Counting and Growth Rate
}

Corey Wilson

University of South Florida

\author{
Advisors: \\ Arcadii Grinshpan, Mathematics and Statistics \\ Jonathan Burns, Mathematics and Statistics \\ Gordon Fox, Biology \\ Philip van Beynen, Geography
}

Problem Suggested By: Philip van Beynen

Follow this and additional works at: https://digitalcommons.usf.edu/ujmm

Part of the Mathematics Commons

UJMM is an open access journal, free to authors and readers, and relies on your support:

Donate Now

\section{Recommended Citation}

Wilson, Corey (2012) "Speleothem Laminae Counting and Growth Rate," Undergraduate Journal of Mathematical Modeling: One + Two: Vol. 4: Iss. 2, Article 7.

DOI: http://dx.doi.org/10.5038/2326-3652.4.2.7

Available at: https://digitalcommons.usf.edu/ujmm/vol4/iss $2 / 7$ 


\title{
Speleothem Laminae Counting and Growth Rate
}

\begin{abstract}
The goal of this project is to determine if there is a correlation between annual laminae in speleothems and Uranium dating. To do this, we counted laminae using high-resolution images and calculated a line of the best fit for the resulting data. We found that our data could supplement Uranium dating, but unless more data is obtained, laminae counting gives relatively imprecise age and growth rate estimates.
\end{abstract}

Keywords

Speleothems, Laminae, Uranium Dating

Creative Commons License

(c) (1) $9 \odot$

This work is licensed under a Creative Commons Attribution-Noncommercial-Share Alike 4.0 License. 


\section{TABLE OF CONTENTS}

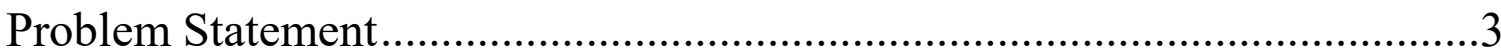

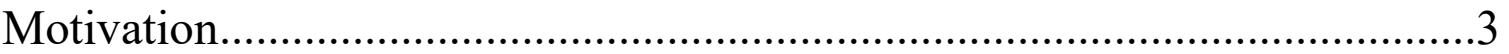

Mathematical Description and Solution Approach ........................................3

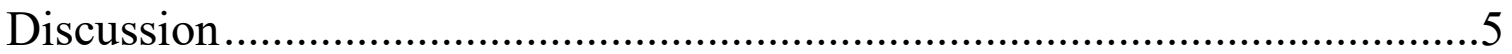

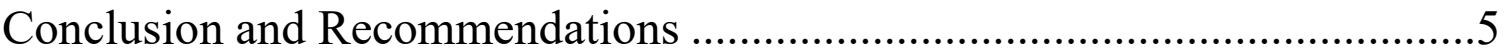

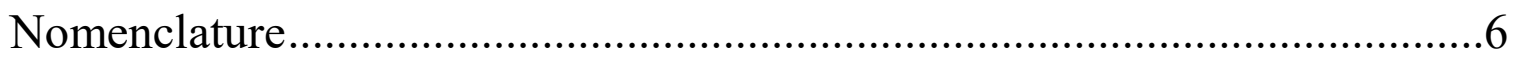

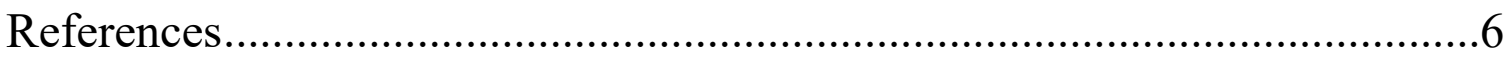

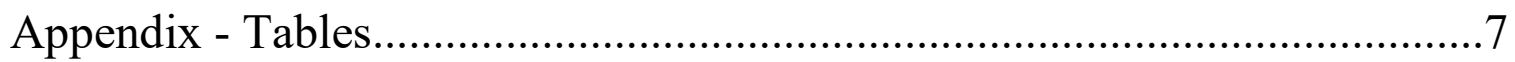

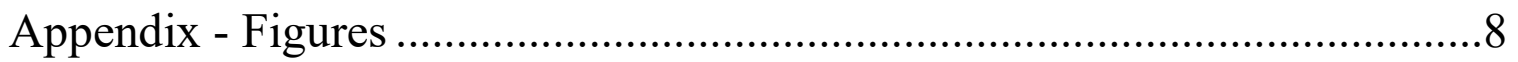




\section{PROBLEM STATEMENT}

Calculate an accurate age and growth rate of a given speleothem using laminae counting.

\section{MOTIVATION}

Uranium dating is often used to determine the age of speleothems. It is a difficult process because the growth of speleothems is affected by various factors. For example, rainfall changes affect the amount of dissolution of limestone, which decreases the amount of deposition within the cave.

Lamina counting has been considered as a possible alternate method to determine the age of speleothems. This approach works in places where wet and dry seasons alternate and affect the laminae coloration (Baker, Smith and Jex). It is conceivable that this dating technique could be used along with Uranium dating to elucidate specific climate events that occurred in the past. We have applied this technique to a speleothem from a known Mayan ritual site to assess a possibility that a specific climate event could have contributed to the collapse of the Mayan empire.

\section{MATHEMATICAL DESCRIPTION AND SOLUTION APPROACH}

The speleothem used in the project was cut and polished by van Beynen. The laminae on this speleothem were counted as follows. First, a cross section of speleothem was laid on a black table to increase the contrast. Then, its photos were taken using a high-resolution camera, measuring the same distance between the speleothem c-axis and the camera. High resolution prints of these photos (see Figure 1, right) were used to count the laminae. The counting was 

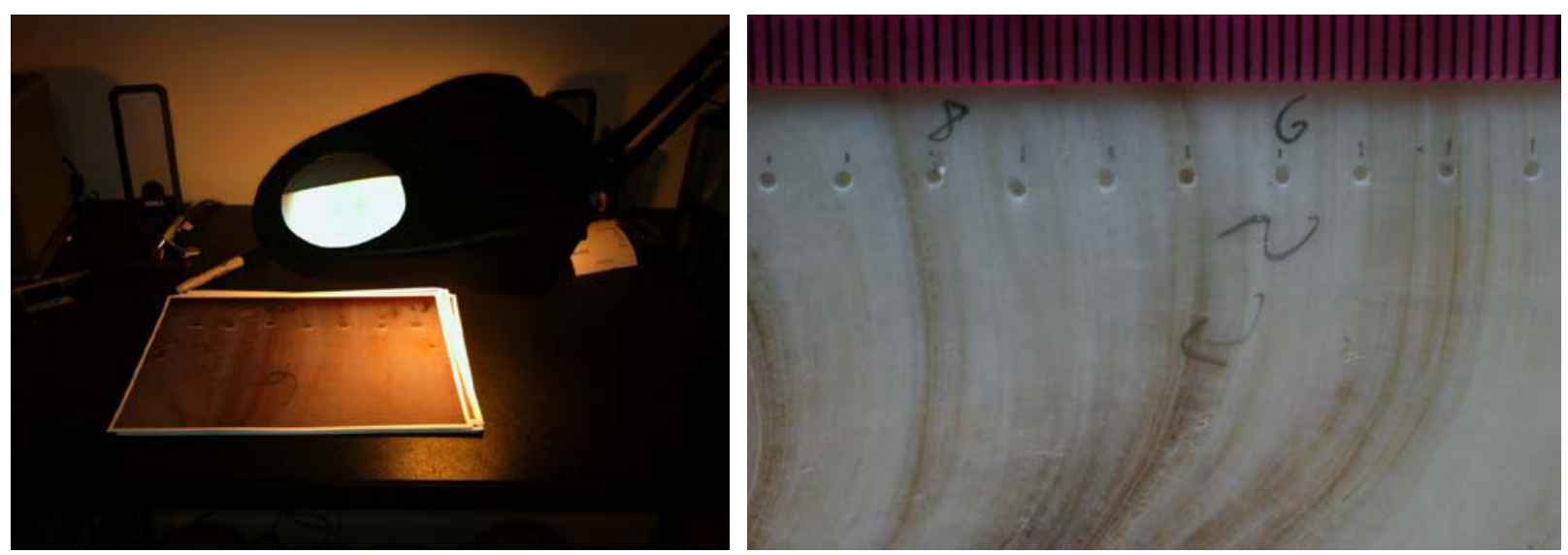

Figure 1: Workplace where the measurements have been taken (left); Close up photograph of the cross section (right).

aided by a desk lamp, a magnifying glass, and a Sharpie marker (see Figure 1, left). For comparison, laminae were marked in the center and the bottom of the images. Once the initial markings were made, the photos were given to Katherine Deberry for additional verification.

The averages of all the counts are presented in Table 1. We have calculated the leastsquares line of the best fit for these counts as $y=m x+b$ where

$$
m=\frac{\sum x y-\frac{\left(\sum x\right)\left(\sum y\right)}{n}}{\sum x^{2}-\frac{\left(\sum x\right)^{2}}{n}} \text { and } b=\bar{y}-m \bar{x}
$$

Here, $n$ stands for the total number of data points while $\bar{x}$ and $\bar{y}$ are the means of the distances and the laminae counts respectively. We have used Microsoft Excel to confirm our findings (see Charts 1-5) and compared the results with van Beynen's radioisotope data (van Beynen). Unfortunately, our results did not correlate with this data well. 


\section{DISCUSSION}

We were able to accurately count the laminae on a speleothem from a known Mayan ritual site. All of the data points turned out to lie on strait line, which we have calculated using the least squares method (and confirm our findings by Microsoft Excel). This suggests that the number of laminae for this speleothem grow linearly with time. Although we were unable to predict speleothem growth based solely on laminae counts, we suspect that these counts could be used to supplement Uranium dating.

\section{CONCLUSION AND RECOMMENDATIONS}

We have studied laminae formation over the entire length of the speleothem and calculated the line of the best fit for each set of measurements that we performed. These lines could be used to predict the number of laminae over time for a specific speleothem or group of speleothems. However we've found it difficult to estimate the age of speleothem based on laminae count without knowing the precise climatic conditions in which it grew. In future, we could use locally grown speleothems to learn how to better account for changes in the climate. Further research and data collection from the same region within this cave are needed to have a greater pool of data for analysis. Specifically, if more usable Uranium dating from a similar speleothem in the same region of the cave with the same connectivity were sampled, a general comparative growth rate could be feasible. 


\section{NOMENCLATURE}

\begin{tabular}{cc}
\hline Symbol & Description \\
\hline $\boldsymbol{m}$ & Slope of a line of the best fit \\
$\boldsymbol{b}$ & y-intercept of a line of the best fit \\
$\boldsymbol{n}$ & number of data points \\
$\overline{\boldsymbol{x}}$ & Mean of the distances \\
$\overline{\mathbf{y}}$ & Mean of the laminae counts \\
\hline
\end{tabular}

\section{REFERENCES}

Baker, A, et al. "Annually Laminated Speleothems: A Review." International Journal of Speleology 37.3 (2008): 193-203.

Larson, Ron, Robert Hostetler and Bruce H Edwards. Calculus: Early Transcendental Functions. 4th. Boston: Houghton Mifflin Company, 2007.

van Beynen, P. Report on Speleothem Work for Xcoch Archaeology. Tampa: University of South Florida, 2010. 


\section{APPENDIX - TABLES}

\begin{tabular}{|c|c|c|c|c|c|}
\hline Distance & Count 1 & Count 2 & Count 3 & Count 4 & Average \\
\hline 2 & 39 & 41 & 54 & 54 & 47.00 \\
\hline 4 & 80 & 82 & 102 & 102 & 91.50 \\
\hline 6 & 143 & 145 & 144 & 144 & 144.00 \\
\hline 8 & 198 & 200 & 215 & 215 & 207.00 \\
\hline 10 & 255 & 258 & 282 & 282 & 269.25 \\
\hline 12 & 303 & 306 & 343 & 344 & 368.75 \\
\hline 14 & 356 & 359 & 406 & 407 & 382.00 \\
\hline 16 & 402 & 405 & 464 & 465 & 434.00 \\
\hline 18 & 438 & 443 & 508 & 509 & 474.50 \\
\hline 20 & 482 & 493 & 570 & 571 & 529.00 \\
\hline 22 & 529 & 538 & 638 & 639 & 586.00 \\
\hline 24 & 564 & 573 & 688 & 689 & 628.50 \\
\hline 26 & 596 & 610 & 757 & 758 & 680.25 \\
\hline 28 & 643 & 657 & 818 & 819 & 734.25 \\
\hline 30 & 683 & 700 & 859 & 860 & 775.50 \\
\hline 32 & 743 & 760 & 912 & 913 & 832.00 \\
\hline 34 & 796 & 813 & 964 & 965 & 884.50 \\
\hline 36 & 838 & 855 & 1003 & 1004 & 925.00 \\
\hline 38 & 881 & 898 & 1041 & 1042 & 965.50 \\
\hline 40 & 936 & 953 & 1090 & 1091 & 1017.50 \\
\hline 42 & 998 & 1015 & 1148 & 1149 & 1077.50 \\
\hline 48 & 1093 & 1110 & 1305 & 1306 & 1203.50 \\
\hline
\end{tabular}

Table 1: Laminae counts at a given distance from the center. Counts 1 through 4 correspond the number of laminae counted at the center (two measurements) and outside (two measurements) respectively. 


\section{APPENDIX - CHARTS}

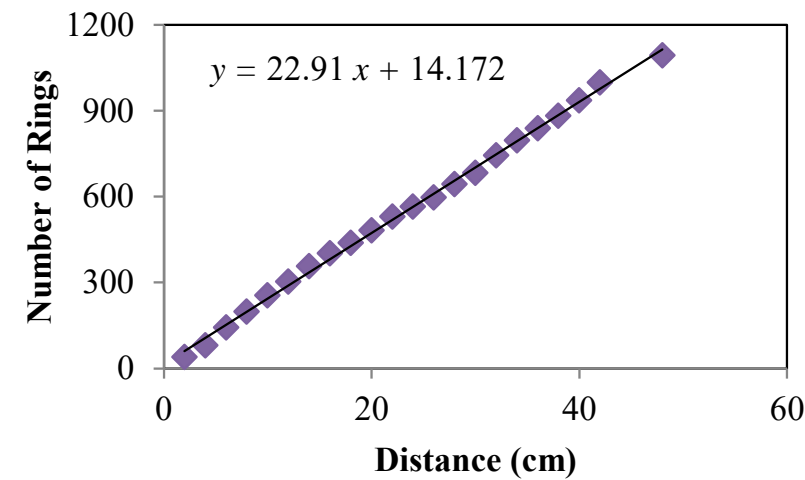

Chart 1: Laminae counts at a specific distance from the center ( $1^{\text {st }}$ count at the center).

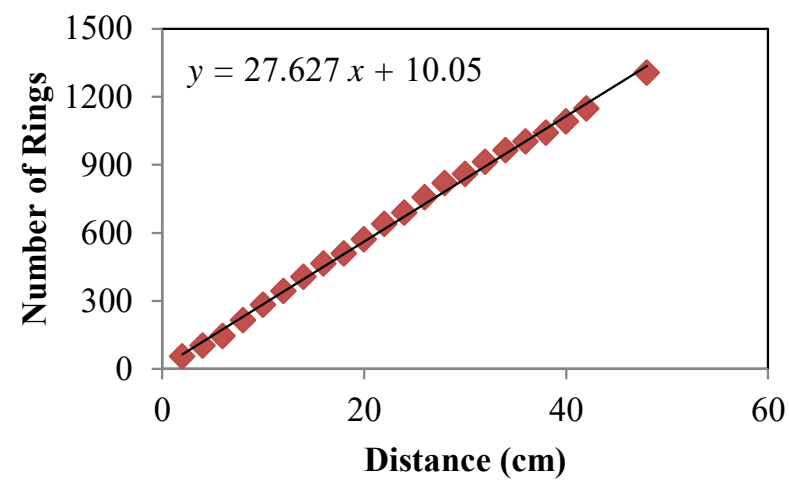

Chart 3: Laminae counts at a specific distance from the center ( $1^{\text {st }}$ outside count).

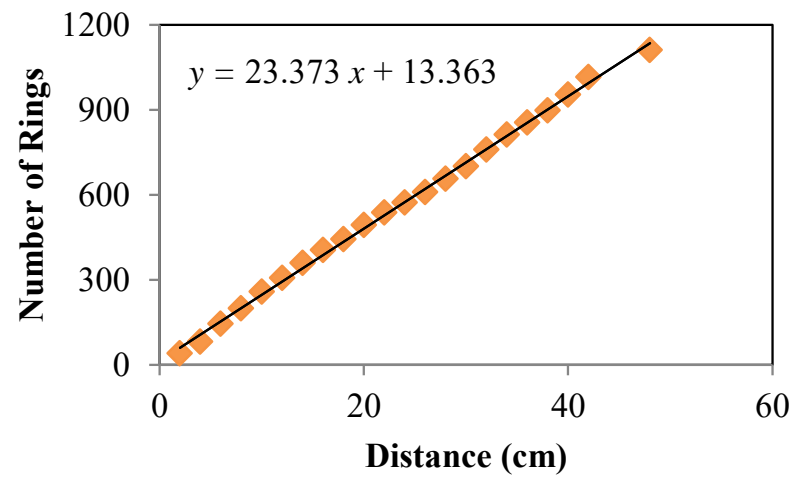

Chart 2: Laminae counts at a specific distance from the center $\left(2^{\text {nd }}\right.$ count at the center $)$.

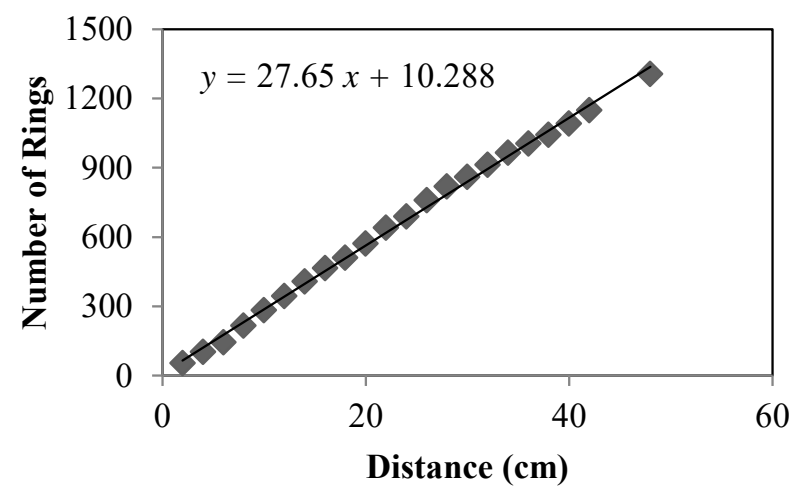

Chart 4: Laminae counts at a specific distance from the center $\left(2^{\text {nd }}\right.$ outside count).

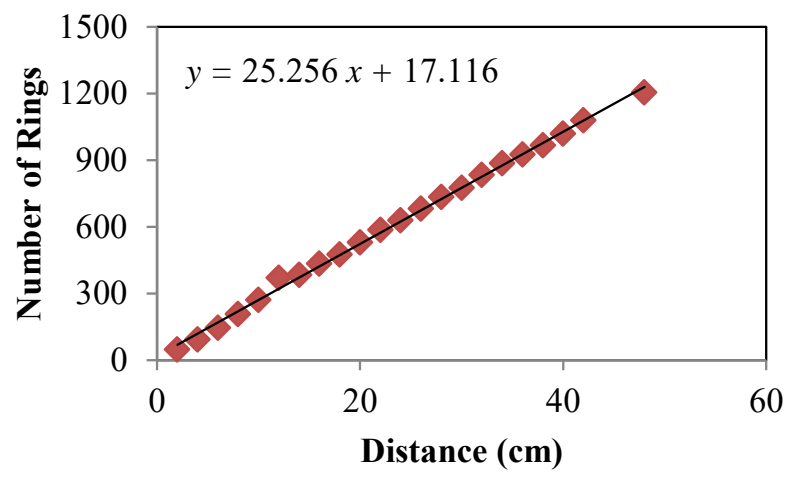

Chart 5: Laminae counts at a specific distance from the center (average of all counts). 